\title{
ДОСЛІДЖЕННЯ МОЖЛИВОСТІ ОТРИМАННЯ ДЕКІЛЬКОХ ФЛАНЦІВ ПО ВИСОТІ ПОРОЖНИСТОЇ ДЕТАЛІ
}

Класифікацію процесів точного об’ємного штампування (ТОШ) видавлюванням в залежності від способу деформування можна побудувати на основі поділу всіх способів на два класи: - базові або прості способі і комбіновані способі, тобто складні процеси, які одержують шляхом об'єднання базових схем деформування. За основу класифікації базових процесів видавлювання приймемо напрямок руху інструменту і течії металу, співвідношення напрямків докладання зовнішніх сил і вид одержуваних деталей. В залежності від співвідношення напрямків руху інструменту і течії металу заготовки видавлювання розділяється на поздовжнє і поперечне. Поздовжнє видавлювання характеризується тим, що в процесі деформації заготовки площа її поперечного перерізу зменшується, а частина деталі, що видавлюється, переміщається уздовж осі вихідної заготовки. Поперечне видавлювання характеризується тим, що видавлюється частина заготовки переміщається під кутом до осі заготовки [1-3].

У процесах поздовжнього і поперечного видавлювання використовуються чотири основних (базових) способи видавлювання: пряме, зворотне, радіальне і бокове видавлювання. Вони відрізняються схемами напружено-деформованого стану та докладання сили тертя, областю використання і видом одержуваних деталей.

При прямому видавлюванні пластична течія металу відбувається в напрямку прикладання сили і збігається з напрямком руху пуансону. Для способу характерне переміщення всієї заготовки уздовж стінок порожнини інструменту (матриці). При зворотному видавлюванні пластична течія металу відбувається в напрямку, протилежному руху пуансона, а відносного ковзання недеформуємої частини заготовки по інструменту не відбувається.

Радіальне видавлювання характеризується поперечною пластичною течією металу в кругову порожнину, що призводить до утворення вісесиметричних деталей з потовщеннями (фланцями). Для бокового видавлювання характерна пластична течія металу в одну або кілька канальних поперечних порожнин з утворенням на деталі відростків різної конфігурації. Поєднаним (відцентровим і доцентровим) поперечним видавлюванням можна утворити потовщення або відростки на зовнішній і внутрішній поверхні трубчастої заготовки $[4,5]$.

Значно розширити можливості отримання складнопрофільних деталей можна шляхом освоєння способів комбінованого видавлювання, заснованих на поєднанні прямого, зворотного і поперечного видавлювання. Процеси комбінованого видавлювання поєднують в собі переваги поздовжнього і поперечного видавлювання. Даним способом можна отримувати деталі більш складної форми в порівнянні з традиційними способами штампування. Застосування процесів комбінованого видавлювання дозволяє збільшити коефіцієнт використання металу до 0,98 за рахунок максимального наближення форми і розмірів заготовок до параметрів готової деталі. Завдяки цьому досягається значна економія металу, зменшується трудомісткість подальшої обробки різанням. Ці особливості дозволяють застосовувати процеси комбінованого видавлювання замість лиття, гарячого штампування і обробки різанням при виробництві заготовок і деталей різної конфігурації з чорних і кольорових металів і їх сплавів [6].

Для отримання складнопрофільних деталей $з$ фланцем доцільно використовувати комбіновані способи штампування видавлюванням, активно регулюючи кінематику течії металу в порожнині штампа. Прості схеми прямого, зворотного і поперечного видавлювання комбінують в різних варіантах, як за часом, так і по шляху деформування за рахунок синхронного або асинхронного переміщення складових частин деформуючого інструменту. 
Комбінування схем радіального і зворотного (прямого) видавлювання відрізняється меншою енергоємністю процесу в порівнянні з багатоперехідним штампуванням, більшою стійкістю вихідної заготовки в області фланця і різноманітністю можливих технологічних схем силового і кінематичного впливу на заготовку [7].

Приклади освоєння комбінованих процесів штампування видавлюванням східчастих стрижневих деталей з фланцем вельми обмежені. Ці процеси вимагають вивчення напружено-деформованого стану, аналізу силового режиму, кінцевого і граничного формозмінення. Тому, для підвищення ефективності процесів точного об'ємного штампування необхідно вирішити завдання, що стоять перед технологами і конструкторами за визначенням силового і кінематичного режимів деформування на основі моделювання комбінованого видавлювання і комбінованого штампування.

Процеси холодного видавлювання відносяться до прогресивних методів обробки тиском і мають ряд технічних і економічних переваг перед іншими процесами обробки металів тиском. Широке поширення у виробництві може отримати комбіноване видавлювання, що дозволяє виготовляти складнопрофільовані деталі унікальної конфігурації.

Характерним недоліком цього процесу є нестійкість швидкостей течії матеріалу в різних напрямках. У виробництві це призводить до того, що технолог повинен задавати значні припуски на обрізку, а якщо вони не виконуються, то деталь вважається остаточним браком, при цьому коефіцієнт використання металу істотно скорочується. За допомогою методу розривних полів швидкостей вирішена задача комбінованого видавлювання деталей типу ступінчастих втулок з додатком протитиском до елементів деталі. Досліджено вплив додаткових сил на кінематику пластичної течії, силові параметри і стійкість процесу деформування [8, 9].

При комбінованому видавлюванні ступінчастої втулки 3 похилою перемичкою деформація локалізується в клинових каналах інструменту, тому для досягнення нестаціонарної стадії необхідно зблизити кромки інструменту до відстані, близької до товщини стінки виробу. Таким чином, стаціонарна стадія займає більшу частину часу деформування, i чим більше нахил перемички, тим більше цей час.

Технологічні схеми деформування в роз'ємних матрицях характеризується орієнтуванням площині роз'єму матриці по відношенню до осі пуансона, числом площин роз'єму матриці, числом переходів штампування і т.д.

Технологічна надійність і ефективність процесів ковальсько-штампувального виробництва багато в чому залежить від стійкості деформувального інструменту, умови роботи якого, як правило, посилюються пропорційно зростанню складності і вимог до якості і точності одержуваних виробів

Процеси точного об'ємного штампування є сучасним рішенням в отриманні деталей з підвищеною якістю та точністю. У порівнянні з іншими способами закрите видавлювання в роз'ємних матрицях має найбільші технологічні можливості. Застосування таких схем деформування дозволяє розширити номенклатуру отримуваних виробів суцільних та пустотілих, вісесиметричних та неосесиметричних виробів. Тому є тенденція до збільшення практичного освоєння подібних процесів [10].

Метою роботи є моделювання силового режиму процесу комбінованого зворотнорадіального видавлювання складнопрофільованої порожнистої деталі і дослідження можливостей формоутворення фланців в суміщеному процесі.

На рис. 1 розглядається схема процесу комбінованого зворотно-радіального видавлювання (а) і отримана деталь (б).

Вихідними даними для моделювання процесу комбінованого зворотно-радіального видавлювання в програмі QForm 2D/3D (на основі методу скінченних елементів) $\epsilon$ :

- матеріал заготовки АМцМ (крива істинних напружень описується рівнянням $\sigma_{\mathrm{s}}(\varepsilon)=188,4 \cdot \varepsilon^{0,15}$, межа плину $\sigma_{0,2}=105$ МПа, модуль Юнга $E=75000$ МПа, коефіцієнт Пуассона $v=0,3$ і коефіцієнт тертя між матеріалом заготовки і інструментом $\mu=0,08$ за законом Зібеля);

$-R_{0}=22,5$ мм $\left(R_{0}-\right.$ радіус заготовки $), R_{1}=18,5$ мм $\left(R_{1}-\right.$ радіус пуансона), $R_{2}=26,5 \mathrm{мм}$ $\left(R_{2}-\right.$ радіус фланця $), L_{0}=45 \mathrm{Mм}\left(L_{0}-\right.$ висота заготовки $), L_{1}=20 \mathrm{Mм}\left(L_{1}-\right.$ відстань між флан- 
цями), $h=4 ; 6 ; 8$ мм ( $h$ - висота приймальної порожнини для фланця в півматрицях, що видавлюється), $\mathrm{t}=4$ мм ( $\mathrm{t}-$ товщина стінки стакана), $r=0,4$ мм $(r-$ радіус заокруглення кромок інструменту);

- силові параметри процесу: $P$ - сила видавлювання, $V$ - швидкість пуансона.

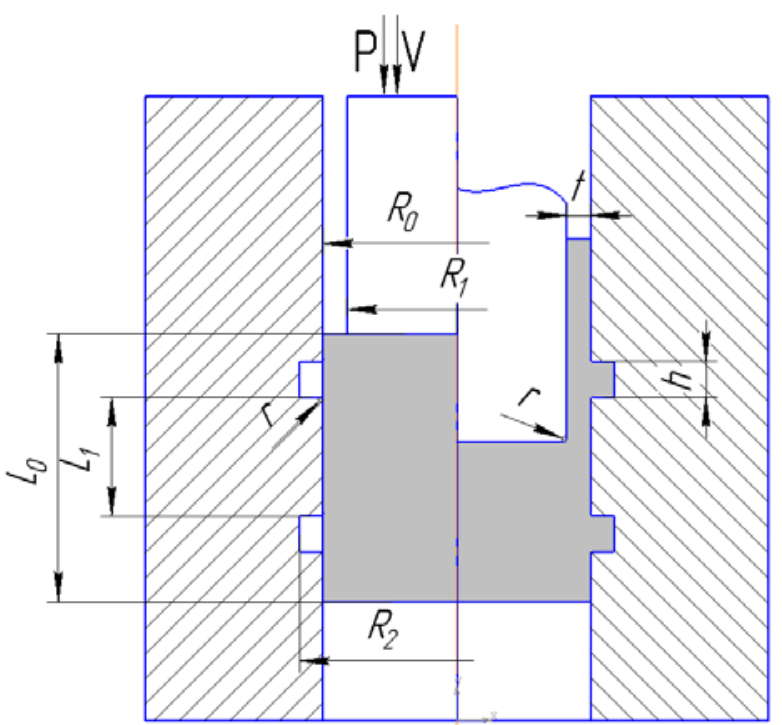

a

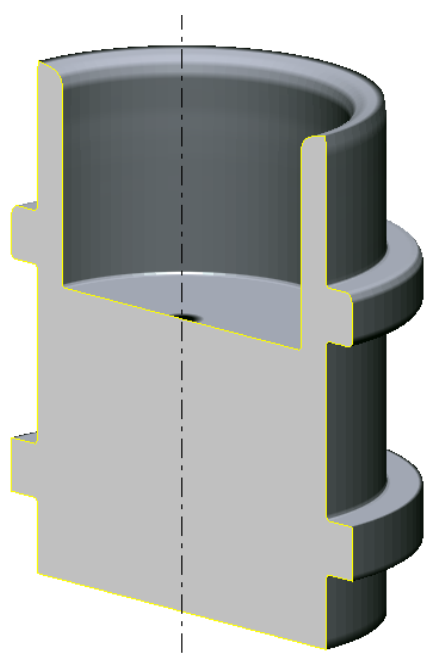

6

Рис. 1. Схема процесу комбінованого зворотно-радіального видавлювання (a) i отримана деталь (б)

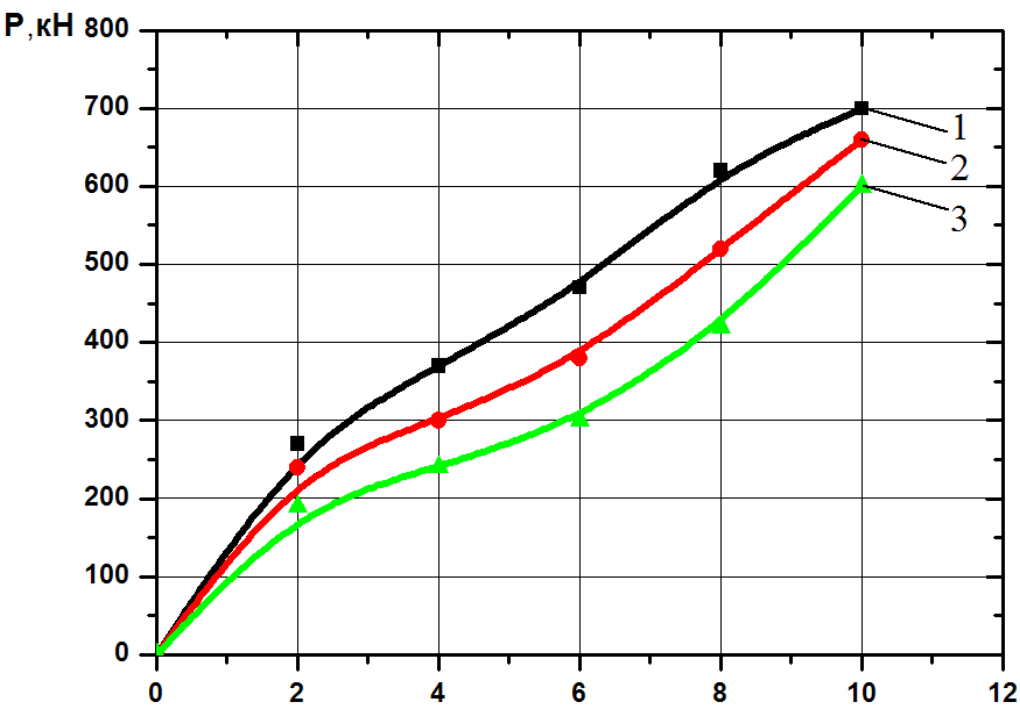

S,MM

крива 1 - відповідає відношенню $\mathrm{h} / \mathrm{t}=1 ;$ крива $2-\mathrm{h} / \mathrm{t}=1,5 ;$ крива $3-\mathrm{h} / \mathrm{t}=2$

Рис. 2. Графік залежності сили видавлювання Р від ходу робочого пуансона $\mathrm{S}$

На рис. 2 представлений графік залежності сили процесу видавлювання від ходу пуансона при різній відносній величині $(\mathrm{h} / \mathrm{t}=1 ; 1,5 ; 2)$, на якому видно, що з ходом пуансона сила видавлювання збільшується. На протязі всього ходу крива 1 знаходиться вище інших (кривої 2 і 3). Тому що крива 1 відповідає найбільшим значенням сили видавлювання Р через найбільшу ступінь деформації та найменшу висоту порожнини для фланців 3 трьох розглянутих випадків. 


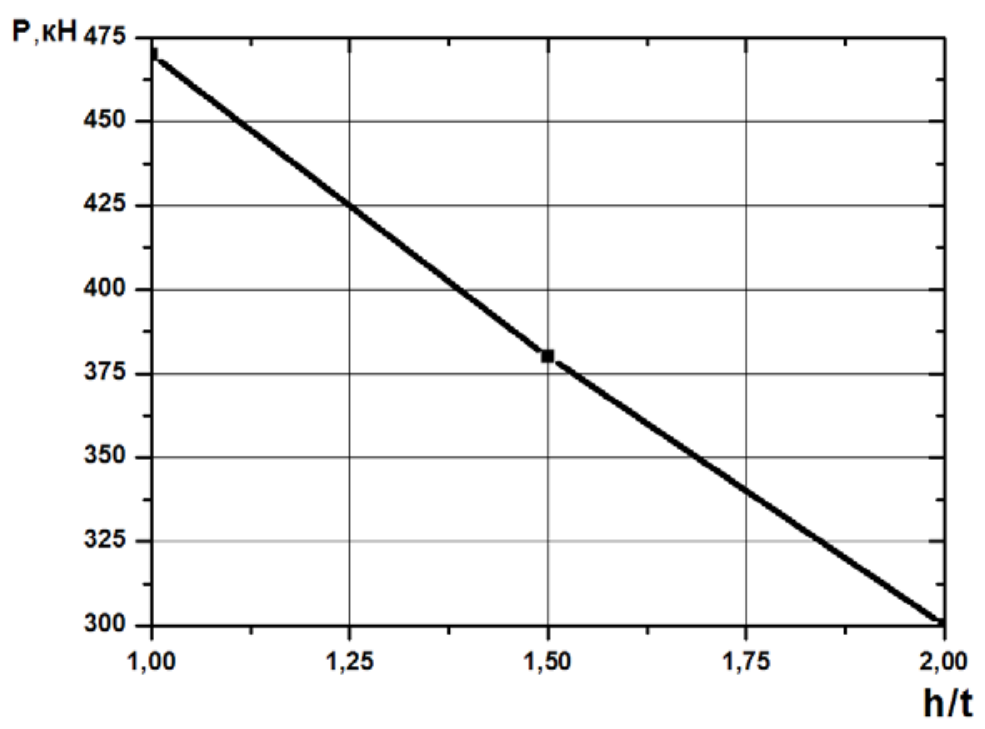

Рис. 3. Графік залежності сили видавлювання $P$ від відносної величини $h / t$ при ході робочого пуансона $\mathrm{S}=6 \mathrm{mм}$

На рис. 3 показаний графік залежності сили видавлювання Р від відносної величини $\mathrm{h} / \mathrm{t}$ при ході робочого пуансона $\mathrm{S}=6$ мм, на якому ми бачимо, що зі збільшенням величини h/t від 1 до 2 значення сили видавлювання зменшується лінійно від 470 до 300 кН, за рахунок зниження можливості перебігу матеріалу в радіальному напрямку.

\section{ВИСНОВКИ}

Розрахунки в Qform 2D/3D підтвердили можливість виготовлення складнопрофільованої порожнистої деталі комбінованим зворотно-радіальним видавлюванням в умовах реального виробництва, також підтвердили що зі збільшенням висоти фланцю зменшується ступінь деформації та сила видавлювання. Наприклад, для ходу пуансона $S=10$ мм при відношенні $h / t=1$ сила видавлювання рівна $P=700$ кН. При переході від відношення $h / t=1,5$ та $h / t=2$ сила видавлювання зменшується відповідно на 4,3 \%. При переході від відношення $h / t=1$ та $\mathrm{h} / \mathrm{t}=2$ сила видавлювання зменшується відповідно на 14,3\%.

\section{СПИСОК ВИКОРИСТАНОЇ ЛІТЕРАТУРИ}

1. Алієв I. С. Методи пошуку нових технологічних способів видавлювання. Теорія та практика обробки матеріалів тиском : колективна монографія. Під ред. Богуслаєва В. О., Бобиря М. І., Тітова В. А., Качана О. Я. Запоріжжя : АТ «МоторСіч», 2016. С. 364-385.

2. Калюжний В. Л., Цибенко А. С., Чувільов Ю. О., Чувільов Є. О. Використання холодного штампування для отримання порожнистого виробу з необхідними властивостями здеформованого металу. Вісник НТУУ «КПІ». Серія машинобудування. 2015. 1(73). С. 124-130.

3. Алиева Л. И. Совершенствование процессов комбинированного выдавливания: монография. Краматорск: ООО «Тираж - 51». 2018. 352 с. ISBN 978-966-379-846-2

4. Абхари П. Б. Исследование деформированного состояния деталей с фланцем в разъемных матрицах. Матеріали 14 Міжнародної науково-технічної конференції. Важке машинобудування. Проблеми та перспективи розвитку. Краматорськ: ДДМА, 2016. С. 8-9.

5. Абхари П. Б. Теоретический анализ процесса выдавливания деталей с фланцем в закрытых матрицах. Вісник Херсонського національного технічного університета. Херсон, 2017. 2 (61). С. 11-18.

6. Алиев И. С., Абхари П. Б. Формоизменение полых деталей с фланцем в процессе холодного выдавливания. Материаль Международной научно-технической конференции. Университетская наука-2017. Мариуполь ПГТУ, 2017. 1. С. 190-191.

7. Алиева Л. И., Абхари П. Б., Ибрагимов А. И., Корденко М. В. Способы управления формообразованием деталей при выдавливании. Матеріали 9 Міжнародної науково-технічної конферениії Ресурсозбереження та енергоефективність процесів і обладнання обробки тиском у машинобудуванні та металургії. Харків: НТУ «ХПІ», 2017. С. 8-10. 
8. Abhari Payman. Investigation of fracture moment in radial extrusion process by finite element method. 18 International scientific conference New technologies and achievements in metallurgy, material engineering, production engineering and physics. Series: Monographs. Częstochowa. 2017. 68, pp. 97-101.

9. Abhari Payman. Numerical simulation of cold forging process to investigate folding defect in enclosed dies. International Journal of Mechanics and Advanced Technologies. 2017.2 (80), pp. 71-77. http://journal.mmi.kpi.ua/author/submission/109198. DOI: http ://dx.doi.org/10.20535/2521-1943.2017.79.96079.

10. Hrudkina N., Aliieva L., Abhari P., Kuznetsov M., Shevtsov S. Derivation of engineering formulas in order to calculate energy-power parameters and a shape change in a semi-finished product in the process of combined extrusion. Eastern-European Journal of Enterprise Technologies. 2019. 2. 7 (98), pp. 49-57. DOI: 10.15587/17294061.2019.160585.

\section{REFERENCES}

1. Aliiev I.S. Methods of searching for new technological methods of extrusion. Theory and practice of material processing by pressure: a collective monograph. Eds. Boguslaev V.O., Bobir M.I., Titov V.A., Kachan O.Ya. Zaporizhia: Motor Sich JSC. 2016, pp. 364-385. (in Ukrainian).

2. Kalyuzhny V.L., Tsybenko A.S., Chuvilov Y.O., Chuvilov E.A. The use of cold stamping to obtain a hollow product with the required properties of the deformed metal. Bulletin of NTUU "KPI". Mechanical engineering series. 2015, 1 (73), pp. 124-130. (in Ukrainian).

3. Aliieva L.I. Improvement of combined extrusion processes: monograph. Kramatorsk: LLC "Tiraj - 51". 2018, 352 p. ISBN 978-966-379-846-2. (in Russian).

4. Abhari P.B. Investigation of the deformed state of parts with a flange in detachable matrices. Proceedings of the 14th International Scientific and Technical Conference. Heavy engineering. Problems and prospects of development. Kramatorsk: DSEA. 2016, pp. 8-9. (in Russian).

5. Abhari P.B. Theoretical analysis of the process of extrusion of parts with a flange in closed matrices. Bulletin of Kherson National Technical University. Kherson. 2017. 2 (61). pp. 11-18. (in Russian).

6. Aliiev I.S., Abhari P.B. Shaping of hollow parts with a flange in the process of cold extrusion. Proceedings of the International Scientific and Technical Conference. University Science-2017. Mariupol: PSTU. 2017, 1, pp. 190-191. (in Russian).

7. Aliieva L.I., Abhari P.B., Ibragimov A.I., Kordenko M.V. Methods of controlling the formation of parts during extrusion. Proceedings of the 9th International Scientific and Technical Conference Resource Conservation and Energy Efficiency of Pressure Processing Processes and Equipment in Mechanical Engineering and Metallurgy. Kharkiv: NTU "KhPI". 2017, pp 8-10. (in Russian).

8. Abhari Payman. Investigation of fracture moment in radial extrusion process by finite element method. 18 International scientific conference New technologies and achievements in metallurgy, material engineering, production engineering and physics. Series: Monographs. Częstochowa. 2017. 68, pp. 97-101.

9. Abhari Payman. Numerical simulation of cold forging process to investigate folding defect in enclosed dies. International Journal of Mechanics and Advanced Technologies. 2017.2 (80), pp. 71-77. http://journal.mmi.kpi.ua/author/submission/109198. DOI: http ://dx.doi.org/10.20535/2521-1943.2017.79.96079.

10. Hrudkina N., Aliieva L., Abhari P., Kuznetsov M., Shevtsov S. Derivation of engineering formulas in order to calculate energy-power parameters and a shape change in a semi-finished product in the process of combined extrusion. Eastern-European Journal of Enterprise Technologies. 2019, 2. 7 (98), pp. 49-57. DOI: 10.15587/17294061.2019.160585.

Абхарі П. Б. $\quad$ - д-р техн. наук, проф., професор кафедри ОМТ ДДМА;

Чучин О. В. - - канд.техн. наук, ст. викладач кафедри ОМТ ДДМА;

Кузенко О. А. - - аспірант кафедри ОМТ ДДМА;

Махмудов К. Д. - канд.техн. наук, професор дДТУ.

ДДМА - Донбаська державна машинобудівна академія, м. Краматорськ.

ДДТУ - Дагестанський державний технічній університет, м. Каспийськ.

E-mail: omd@dgma.donetsk.ua 